\title{
3. Remote Sensing for Natural or Man-made Disasters and Environmental Changes
} by Alessandro Novellino ${ }^{1}$, Colm Jordan ${ }^{1}$, Gisela Ager ${ }^{1}$, Luke Bateson ${ }^{1}$, Claire Fleming ${ }^{1}$, Kay Smith ${ }^{1}$, Pierluigi Confuorto ${ }^{2}$

${ }^{1}$ British Geological Survey, Nicker Hill, Keyworth NG12 5GG, UK

${ }^{2}$ Federico II University of Naples, Largo San Marcellino 10, 80138 Naples, Italy.

\begin{abstract}
Natural and man-made disasters have become an issue of growing concern throughout the world. The frequency and magnitude of disasters threatening large populations living in diverse environments, is rapidly increasing in recent years across the world due to demographic growth, inducing to urban sprawls into hazardous areas. These disasters also have far-reaching implications on sustainable development through social, economic and environmental impact.

This chapter summarises three scientific contributions from relevant experiences of the British Geological Survey and the Federico II University of Naples, where remote sensing sensors have been playing a crucial role to potentially support disaster management studies in areas affected by natural hazards. The three cases are: the landslide inventory map of St Lucia island, tsunami-induced damage along the Sendai coast (Japan) and the landslide geotechnical characterization in Papanice (Italy). For each case study we report the main issue, datasets available and results achieved.

Finally, we analyse how recent developments and improved satellite and sensor technologies can support in overcoming the current limitations of using remotely sensed data in disaster management so to fully utilize the capabilities of remote sensing in disaster management and strength cooperation and collaboration between relevant stakeholders including end users.
\end{abstract}

Keywords: Earth Observation; geohazards; landslide; tsunami;

\subsection{Introduction}

In 2016, 342 disasters triggered by natural hazards were registered with 564.4 million people reported affected and US\$154 billion estimated cost of damages (Guha-Sapir et al., 2016).

Spawned by the need to rapidly collect vital information to support damage assessment and to assist evaluation and rehabilitation plans, technology innovations have often helped academics, planners, practitioners, policy makers and local communities to assess the potential impact of disasters more efficiently and rapidly, and to track and monitor progress of prevention operations. One technology, which has had an enormous impact on the whole disaster management cycle (response, recovery, mitigation and preparation stage), has been remote sensing. An increasing number of studies have elaborated on the importance and applications of remote sensing in disaster management (Bello and Aina, 2014). A major reason for the adoption of remote sensing is that it is one of the fastest means of acquiring data in timely and cost effective manner up to regional-scale during pre-disaster and post-disaster studies (Williams et al., 2018), with recent international collaborations and 
programs exploiting remote sensing technologies to rapidly assist hazard science and response (Kaku and Held, 2013). For example, ARIA from JPL and Caltech, Copernicus from the European Space Agency (ESA) and Sentinel-ASIA from the Asia-Pacific Regional Space Agency Forum.

As a matter of fact, the field of satellite remote sensing has registered massive developments as a result of sensible technological improvements, which led to higher spatial resolution optical and radar systems, hyperspectral sensors, important by-products such as Interferometric Synthetic Aperture Radar (InSAR) ground deformation maps (Novellino et al., 2017) and development of new processing techniques using machine learning systems, able to access and deal with large volumes of data (Lary et al., 2016).

This chapter contains a collection of three case studies focussed on different application of Earth Observation (EO) techniques for investigating geohazards: St Lucia and Sendai case studies conducted by the British Geological Survey (BGS) and the Papanice case study from the University of Naples (Italy).

\subsection{St Lucia case study}

Due to its location in the Atlantic hurricane belt, the St Lucia island is prone to hurricanes. Its volcanic terrains (Wohletz et al., 1986), together with heavy rainfalls, are inclined to floods and landslides. Also, being placed at the border of a tectonic plate, it faces the threat of earthquakes and tsunamis. Moreover, sea level rise is expected to affect Caribbean countries' coastlines. Consequently, St Lucia, along with the other small island Caribbean nations, has to carefully determine areas for further development to avoid the creation of new risks. In the framework of the European Space Agency (ESA) eoworld2 initiative, EO-derived thematic layers have been delivered to the World Bank by BGS using a combination of satellite EO data, ground validation exercises and pre-existing data (ESA, 2016).

The land use map at $2 \mathrm{~m}$ resolution was predominantly mapped through a combination of automated classification and visual interpretation of high resolution Pleiades satellite imagery (acquired between 2013-2014) and integration, over cloud covered areas, of RapidEye satellite imagery (acquired 2010-2014) and existing land use data (Fig. 3.2.1). 


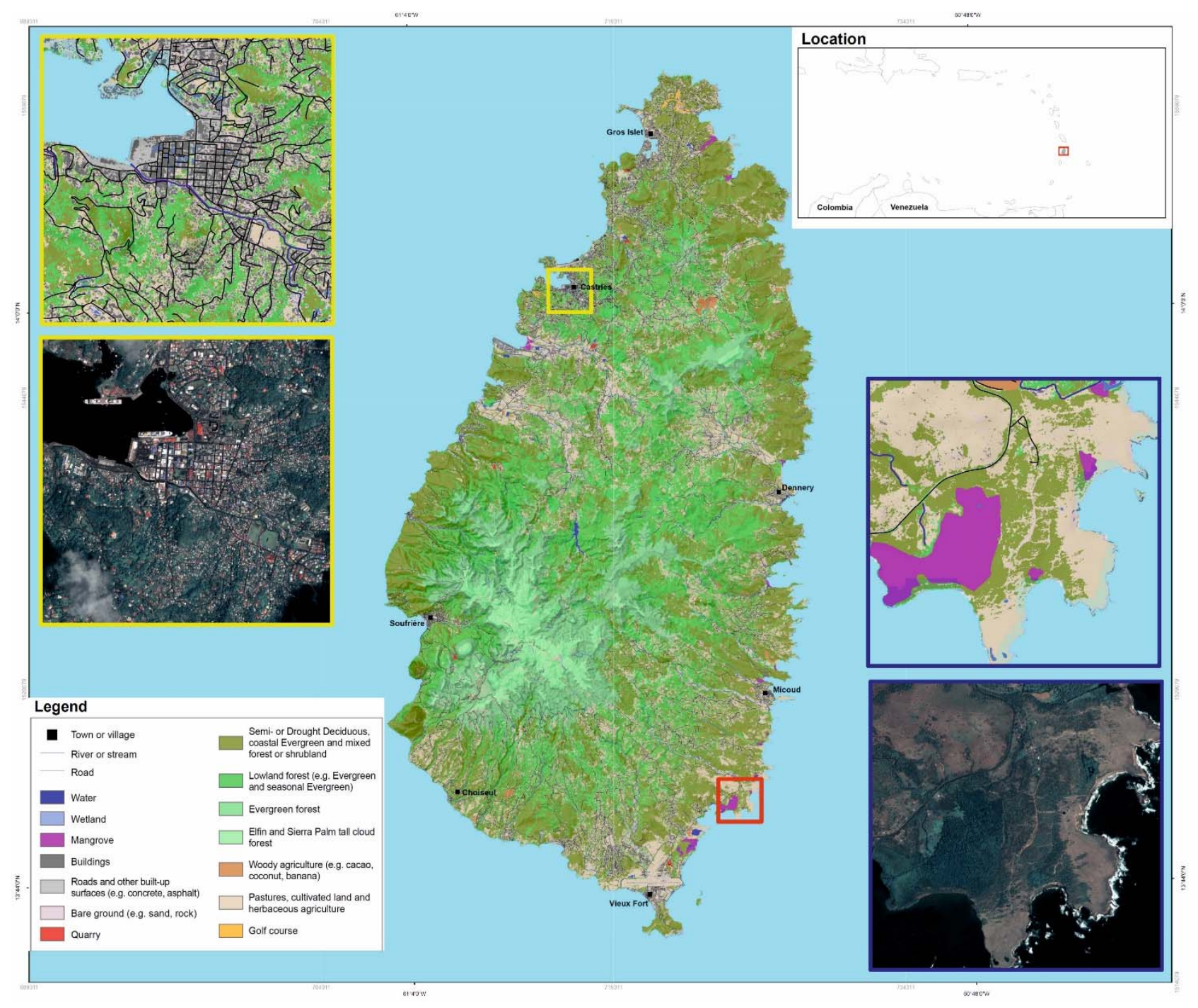

Fig. 3.2.1 - The land use maps generated for Saint Lucia (modified from Jordan et al., 2015).

In Saint Lucia the landslide inventories have been typically produced using conventional field surveys. However, if landslides are taking place in remote areas, inventories often cannot provide a reliable and full catalogue of the spatial distribution of event occurrences. Thus, relatively few of them are being recorded and monitored over time. The EO-based multi-temporal landslides inventory created for this project covered the island of Saint Lucia for the years of 2011-2014 (Fig. 3.2.2). As a result, 1,233 landslide polygons have been detected (compared to the 712 events recorded in the 1995 inventory) and the resulting time series captured two major trigger events: the 2010 Hurricane Tomas and the 2013 Christmas Trough. The study has found that many of the smaller rural roads in the interior were dramatically affected by both events. Moreover, landslides triggered by Hurricane Tomas were rapidly covered by vegetation indicating a quick rate of recovery of the landscape, although, many events were re-activated during the Christmas Trough indicating an increased sensitivity of the landscape to disturbance, and thus higher disaster risk. Extending the multi-temporal record with new acquisitions allowed to create further insights into landscape response to the triggers and this will be vital in establishing relevant hazard and risk assessments. 

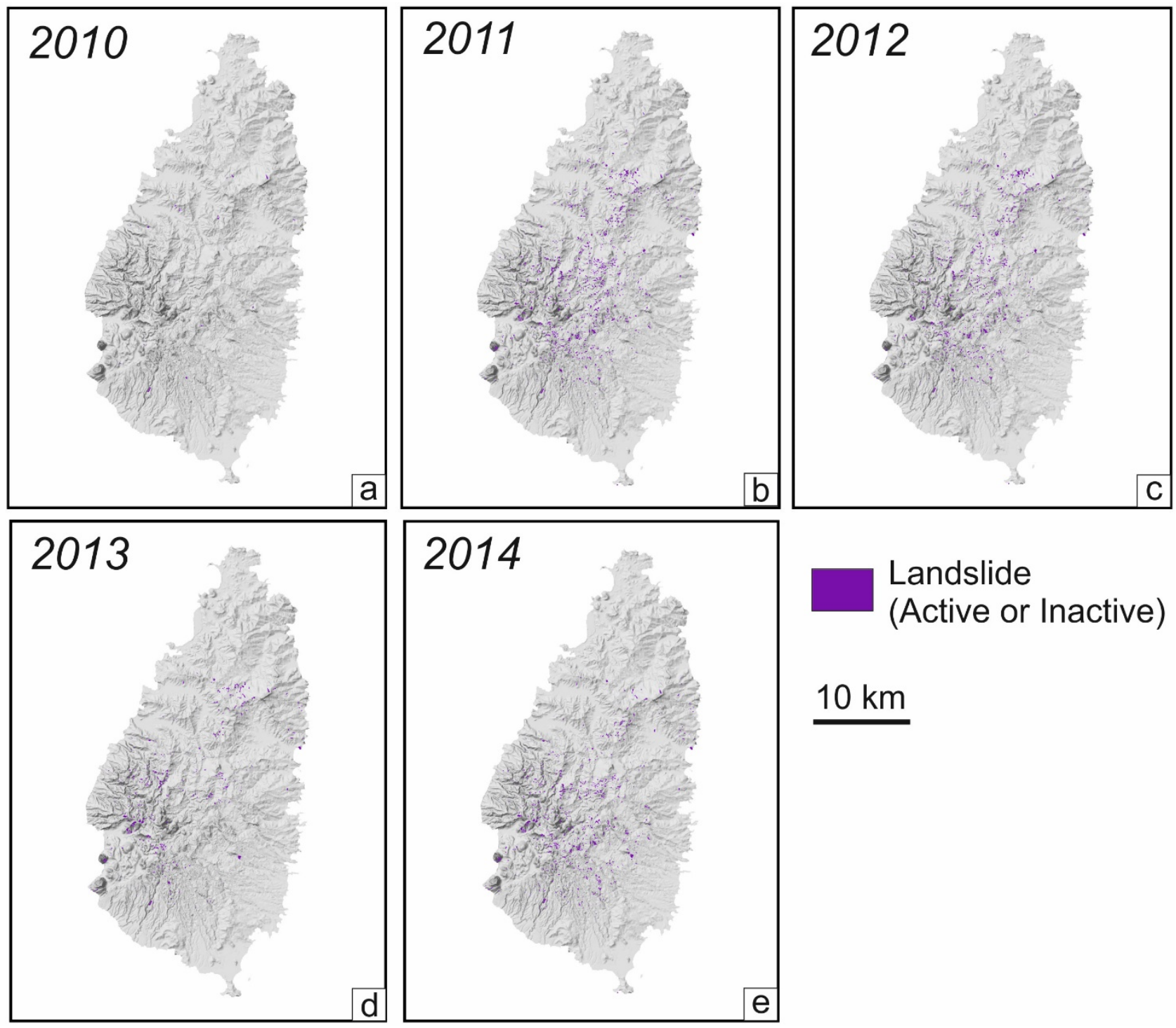

$10 \mathrm{~km}$

Fig. 3.2.2 - Landslide inventory maps of St Lucia showing the distribution of active landslides (modified from Jordan et al., 2015).

The project supported capacity development within government departments, among land owners and the general public. Several workshops on the use of geo-data for landslide and flood hazard and risk assessment were organized and included a range of stakeholders from World Bank to international development agencies.

\subsection{Papanice case study}

Landslides in Italy are among the primary cause of death caused by natural hazards (Guzzetti et al., 2012), as well as of economic losses. Monitoring of such phenomena is of capital importance for public administrations, aiming at the reduction of potential risks. In Papanice, a small hamlet in the province of Crotone (Southern Italy), the post-failure phase of a complex landslide, in the aftermath of a severe rainfall $(185 \mathrm{~mm}$ in the three days preceding the activation, on February 23,2012 ) has 
been remotely monitored by means of multi-temporal InSAR, which provided ground displacement estimates at millimetre precision from TerraSAR-X images, acquired between October 2013 and October 2014 (Confuorto et al., 2017). Such analysis has been integrated with geomorphological surveys and in situ measurements (boreholes, inclinometers and piezometers), leading to a complete characterization of the landslide. InSAR processing showed a deformation pattern along the main scarp of the landslide, with average displacement of $-40 \mathrm{~mm} / \mathrm{yr}$ (along the radar Line of Sight - LOS) in the NW sector, of about $-35 \mathrm{~mm} / \mathrm{yr}$ in the central sector and mean values of -5.8 $\mathrm{mm} / \mathrm{yr}$ in the SE sector (fig. 3.3.1).
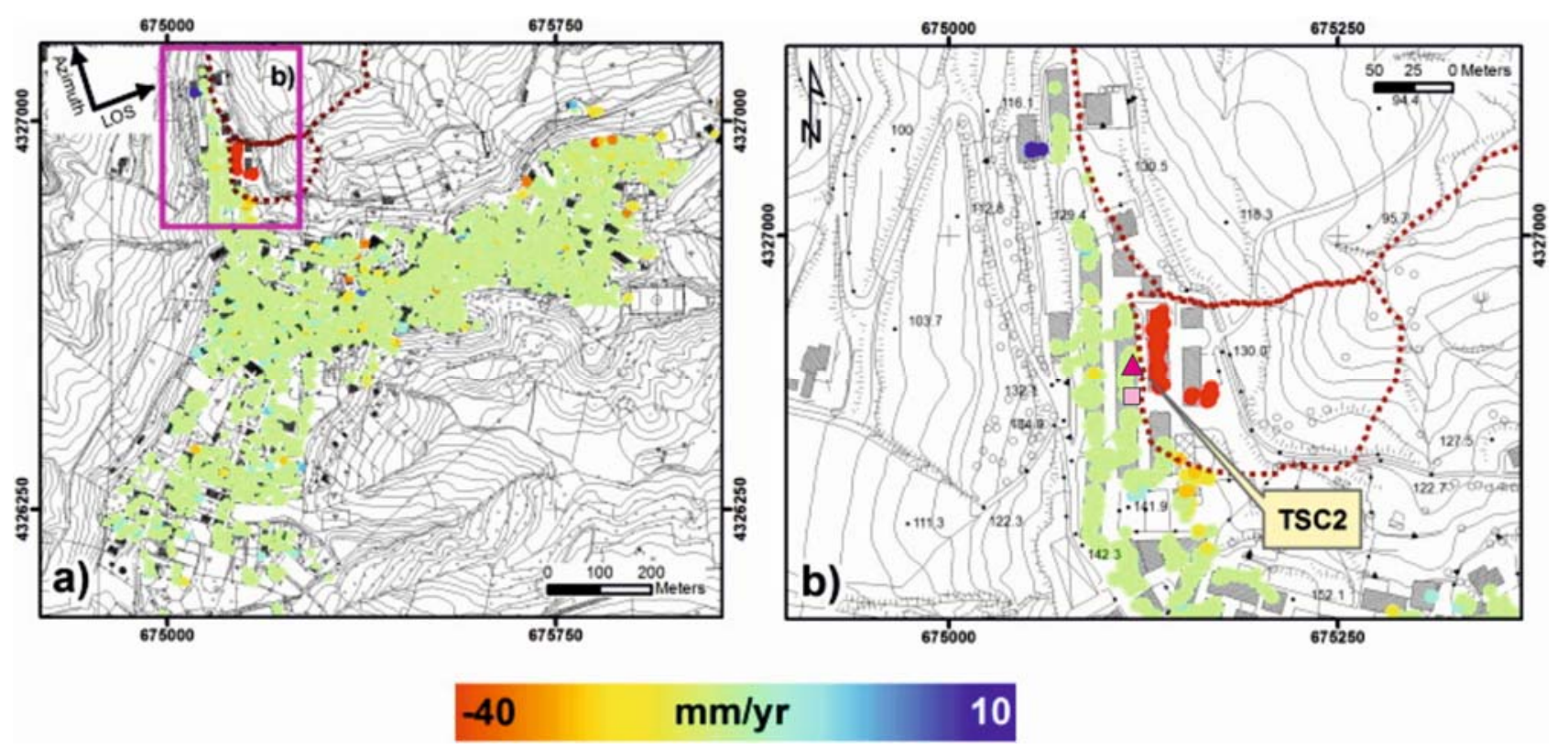

Fig. 3.3.1 - Displacement rate map obtained with the InSAR processing for the time interval 2013-2014. In the purple rectangle, a zoom in of the area of interest (b). Landslides have been reported in brown-dashed line. The point TSC2 has been selected for the time series analysis. The piezometer location is indicated by the purple triangle, the inclinometer by the pink square (modified from Confuorto et al., 2017).

Time series analysis confirms that the stability of the slope is regulated by piezometric level, depending, in turn, by rainfall data: a slowdown of the movement is reached when the groundwater is at $0.8 \mathrm{~m}$ below the ground surface, thus confirming the connection between groundwater presence and triggering/reactivation of slow-moving landslides (fig. 3.3.2). For the Papanice case study, the integration between remote sensing and traditional geological/geotechnical investigations has suggested the installation of a superficial drainage system as best intervention to mitigate the risk. 


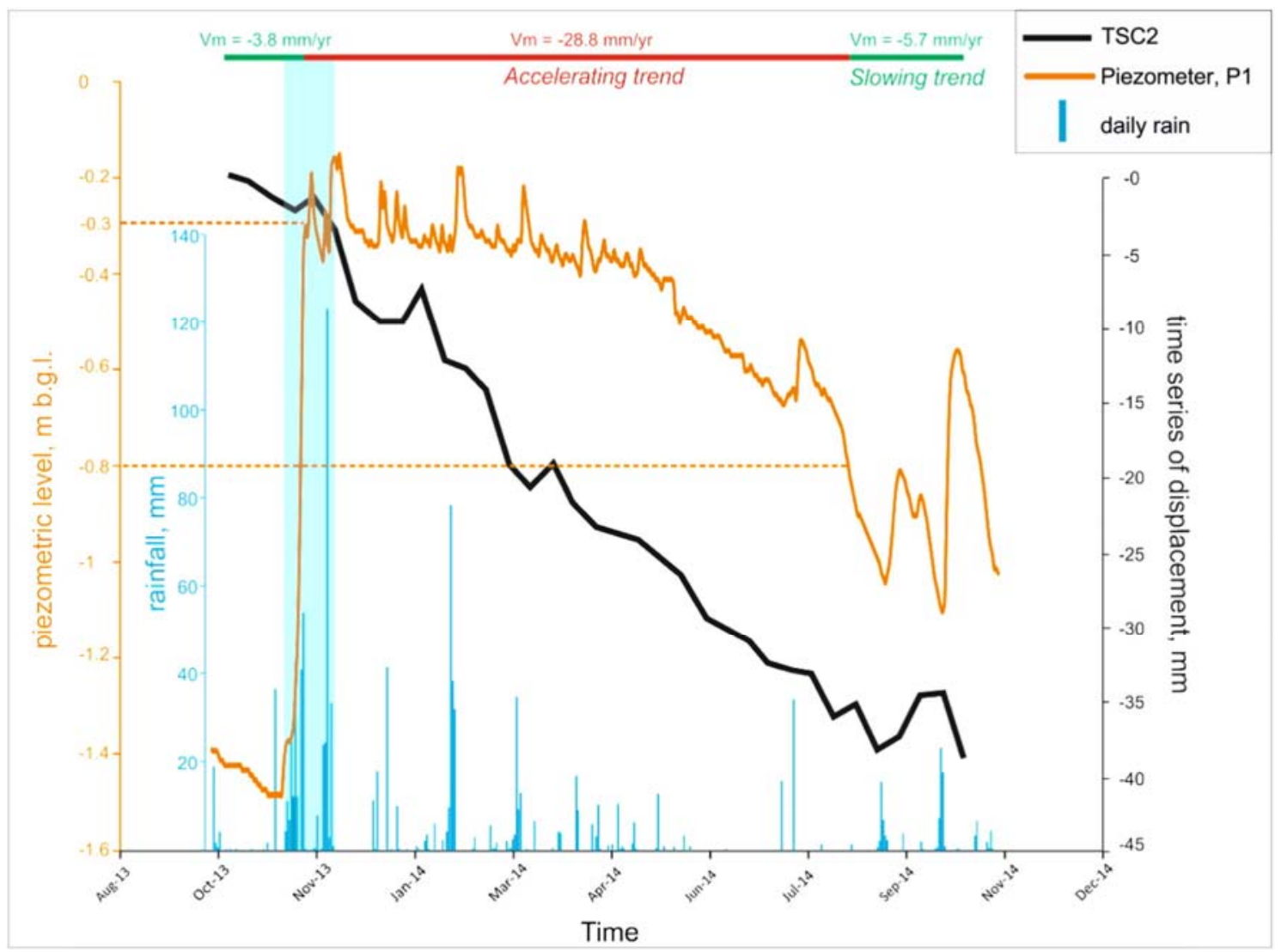

Fig. 3.3.2 - Comparison between piezometric and rainfall data with time series. On the top bar, the average trends of the TSC2 time series (see figure 3.3.1 for its location). The average LOS velocities are shown for the slowing and accelerating trends. Dashed lines show the connection between piezometric level and acceleration and deceleration of the ground movement. The blue shaded column is for the rainy period between November 11, 2013 and December 4, 2013, correspondent to a rapid rise of piezometric level (from Confuorto et al., 2017).

\subsection{Sendai case study}

The Tohoku-oki tsunami following the $11^{\text {th }}$ of March 2011 Mw 9.0 Tohoku-Oki earthquake (Japan) was the most devastating tsunami to strike Japan in recorded history (Simons et al., 2011) with local tsunami heights above sea level at a maximum of $40 \mathrm{~m}$ along the coast of northern Honshu, where offshore seabed gradients are steep, and funnelling along coastal valleys resulted in intense focussing of the wave (Shimozono et al., 2012).

For this case study, we used multi-temporal high-resolution satellite data to map changes in coastal morphology and sedimentary regime from tsunami impact along a $15 \mathrm{~km}$ section of the Sendai Plain between the Natori and Abukuma rivers (Fig. 3.4.1). A specific objective was to identify any differences between those coasts protected by hard engineered structures and those without (Tappin et al., 2012). 

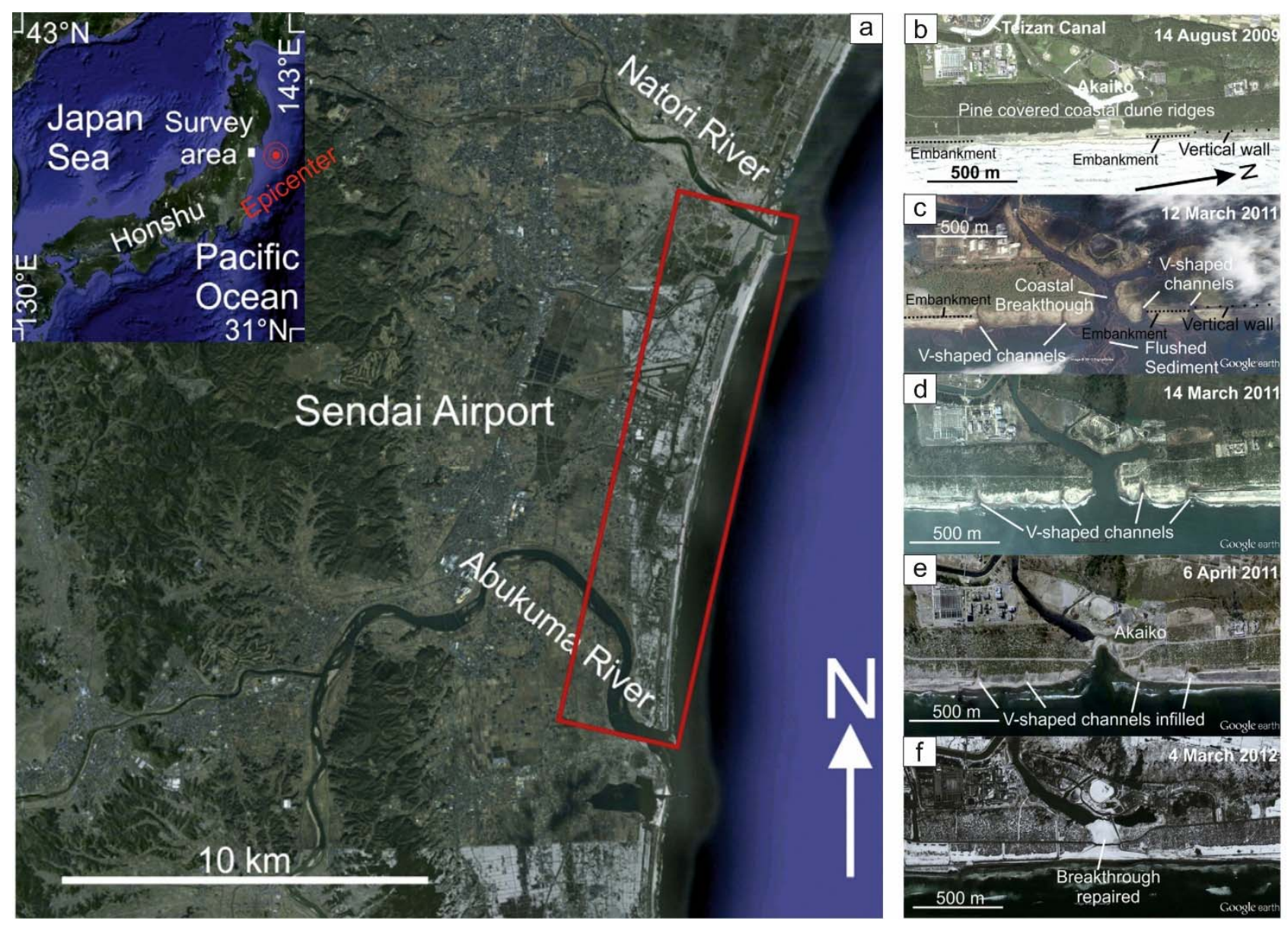

3.4.1 - The Tohoku coast on the island of Honshu, Japan (inset) and study area (red box) along the Sendai coastal plain between the Natori and Abukuma Rivers (a). Southern Sector: time series satellite images of the Akaiko showing the evolution from before the tsunami to the present. B: 14 August 2009 (pre-tsunami). C: 12 March 2011. D: 14 March 2011. E: 6 April 2011, F. 4 March 2012 (modified from Tappin et al., 2012).

In the central part, close to the Sendai Airport, the beach is between 65 and $30 \mathrm{~m}$ wide and narrows northward with a continuous protection of tetrapods and concrete blocks along the shoreface along with engineered embankments above the land on either side (fig. 3.4.1a). Since the 2009, satellite images show minor modification of the beach (fig. 3.4.1b). In post-tsunami satellite imagery, the sea has broken through the coastal barrier in the centre of the area and the Akaiko is now connected to the sea through V-shaped channels on the beach with a seaward opening up to $100 \mathrm{~m}$ (3.4.1c). Comparison of the before and after tsunami imagery indicates that there is little change in the sea level at the beach, the landward limit of the tide line remains the same apart from the coastal breakthrough between Figure 3.4.1b and Figure 3.4.1c, and then the gradual healing of the breach through Figure 3.4.1d and Figure 3.4.1e, to the full repair in Figure 3.4.1f.

The research assessed the tsunami impact on the coast, but also succeeded in mapping the spatiotemporal trajectories of damage and reconstruction activities in the area (Tappin et al., 2012). Furthermore, the results can provide additional evidences for quantifying the effect of the coastal erosion and protecting low-lying areas from flooding. 


\subsection{Discussion and conclusions}

The three case studies show how EO has reached a high level of maturity for the investigation, assessment and monitoring of geohazards at multiple scales and in different geological settings. However, they also prove that field verification remains an essential tool to ascertain the validity of image interpretations.

The increasing trend of EO-based studies is mainly driven by the cascade of new spaceborne/airborne sensors and techniques developed especially during the last ten years, which has been possible with the advent of better sensing technologies, improvements in computational resources for running large-scale model simulations and easy accessibility to knowledge and data fostered by the internet with, for example, open-source programs. These processes have consequently enabled the collection, storage, and processing of EO data on crowd-sourced and distributed environments such as cloud platforms, where they can be more effectively analysed and easily shared on a real-time basis through web technologies, social media, and mobile devices.

All these recent advances, have improved the capabilities of EO data acquisition and analysis, and are resulting in the development of 'best-practice' environmental information accessible by planners and decision makers, which enable us to manage geohazards better. Finally, these studies prove that, if done beforehand, could help in identifying particularly vulnerable areas in other parts of the world that could be prone to similar failures and enabling efficient monitoring solutions. 


\section{Reference List}

Bello, O. M., \& Aina, Y. A. (2014). Satellite remote sensing as a tool in disaster management and sustainable development: towards a synergistic approach. Procedia-Social and Behavioral Sciences, 120, 365-373.

Confuorto, P., Di Martire, D., Centolanza, G., Iglesias, R., Mallorqui, J.J., Novellino, A., Plank, S., Ramondini, M., Thuro, K., Calcaterra, D., 2017. Post-failure evolution analysis of a rainfall-triggered landslide by multi-temporal interferometry SAR approaches integrated with geotechnical analysis. Remote Sens. Environ. 188:51-72. http://dx.doi.org/10.1016/j.rse.2016.11.002.

ESA, 2016. Earth Observation for sustainable development. Partnership Report, September 2016.

Guha-Sapir D, Hoyois Ph., Wallemacq P. Below. R. Annual Disaster Statistical Review 2016: The Numbers and Trends. Brussels: CRED; 2016.

Guzzetti, F., Mondini, A.C., Cardinali, M., Fiorucci, F., Santangelo, M., Chang, K.-T., 2012. Landslide inventory maps: new tools for an old problem. Earth Sci. Rev. 112 (1-2): 42-66. http://dx.doi.org/10.1016/j.earscirev.2012.02.001.

Jordan, C., Grebby, S., Dijkstra, T., Dashwood, C., Cigna, F. 2015. Risk Information Services for Disaster Risk Management (drm) in the Caribbean: operational documentation. Nottingham, UK, British Geological Survey, 69pp. (OR/15/001) (Unpublished).

Kaku, K. and Held, A., 2013. Sentinel Asia: A space-based disaster management support system in the Asia-Pacific region. International Journal of Disaster Risk Reduction, 6, 1-17.

Lary, D.J., Alavi, A.H., Gandomi, A.H. and Walker, A.L., 2016. Machine learning in geosciences and remote sensing. Geoscience Frontiers, 7(1), pp.3-10.

Novellino, A., Cigna, F., Brahmi, M., Sowter, A., Bateson, L., \& Marsh, S. (2017). Assessing the feasibility of a national InSAR ground deformation map of Great Britain with Sentinel-1. Geosciences, 7(2), 19.

Simons, M., Minson, S.E., Sladen, A., Ortega, F., Jiang, J., Owen, S.E., Meng, L., Ampuero, J.P., Wei, S., Chu, R. and Helmberger, D.V., 2011. The 2011 magnitude 9.0 Tohoku-Oki earthquake: Mosaicking the megathrust from seconds to centuries. science, 332(6036), pp.1421-1425.

Tappin, D.R., Evans, H.M., Jordan, C.J., Richmond, B., Sugawara, D. and Goto, K., 2012. Coastal changes in the Sendai area from the impact of the 2011 Tōhoku-oki tsunami: Interpretations of time series satellite images, helicopter-borne video footage and field observations. Sedimentary Geology, 282, 151-174.

Williams, J. G., Rosser, N. J., Kincey, M. E., Benjamin, J., Oven, K. J., Densmore, A. L., Milledge, D. G., Robinson, T. R., Jordan, C. A., and Dijkstra, T. A.: Satellite-based emergency mapping using optical imagery: experience and reflections from the 2015 Nepal earthquakes, Nat. Hazards Earth Syst. Sci., 18, 185-205, https://doi.org/10.5194/nhess-18-1852018, 2018.

Wohletz, K., Heiken, G., Ander, M., Goff, F., Vuataz, F.D. and Wadge, G., 1986. The Qualibou Caldera, St. Lucia, West Indies. Journal of volcanology and geothermal research, 27(1-2), 77-115.

\section{Acknowledgments}

This publication benefited from inputs and contributions from the following: D. Calcaterra, D. Di Martire, M. Ramondini (University of Naples) and Hussain E. (British Geological Survey). Thanks also to the editors of the special issue in which this chapter is published, for their guidance and patience. Data for the St Lucia case study have been obtained through the ESA eoworld2 initiative. 